\title{
Career Path and Political Stability: Factors for Leaving Indonesia?
}

\author{
Tutik Inayati1,2, Takeshi Arai'1, Utomo Sarjono Putro² \\ ${ }^{1}$ Department of Industrial Administration, Tokyo University of Science, Noda, Japan \\ ${ }^{2}$ School of Business and Management, Institut Teknologi Bandung, Bandung, Indonesia \\ Email: tutik.inayati@sbm-itb.ac.id
}

Received July 2014

\begin{abstract}
This study focuses on the relationship between factors career path and political stability on the decision making whether to live in Indonesia or to live abroad as their future plans; if they do, what the odds ratio is in each factor to their decisions. This study uses descriptive statistics and binary logistic regression model as the analysis tools for achieving this study's objectives on fifty respondents. The result shows that most of the respondents are Indonesian male students, while pursuing undergraduate degree abroad with their intention mostly to return home as their future plans. The correlation between career path and political stability is low and negative. The model is not fit, but still at an acceptable level since the significance level is high; it shows that career path will increase the odds ratio people to move abroad or stay abroad almost 3 times likely, while political stability will increase the odds of people to stay abroad by $50 \%$.
\end{abstract}

\section{Keywords}

\section{Career Path, Political Stability, Staying Intention, Binary Logistic Regression Model}

\section{Introduction}

The mobility of scientists and engineers are inevitable; and most of the mobilizations are centralized in several developed countries. Although nowadays new countries have emerged as destination countries for students and professionals in science and engineering area, top destinations have deliberately stood up among others. The movement is caused mainly by the large demand of scientists and engineers in a country. Also, policies by the government in a country concerning immigration policies, especially for highly skilled people, also become a factor of the movement.

This study questions whether two distinctive factors, career path and political stability, influence the decision of people to live in their home countries or to move abroad. Political stability is one fundamental external factor that influences the whole condition of a country, including the economic and social factor, as concluded by Fatah et al. (2012) [1] that political freedom, among several other variables, is a significant determinant of economic growth. Meanwhile, career path is the internal factor of a person to develop himself or herself further and to gain more welfare (social and economic). The implication of this study will also explain the how significant 
these factors influence people's decision. There are more factors that should be inserted, but for now we will focus on these two variables.

In this paper we conducted a questionnaire on 50 Indonesian respondents (students and professionals), with tertiary degree particularly in science and technology fields and abroad. Why are students included in this study? The attraction and the network opening of international labour market begin at the stage of educational pursuit, particularly tertiary degree. Although the number of respondents is not large, it still represents the population of students and professionals with the similar characteristics.

\section{Literature Reviews}

\subsection{High-Skilled Workers}

High skilled workers are defined of those who achieved university degree or extensive experience in a given field [2]. The categories include skilled specialists, independent executives and senior managers, specialized technicians or tradespeople, investors, physicians, business people, "keyworkers" and subcontract workers (OECD SOPEMI, 1997:21) [3]. The movement of high skilled workers lead us to the migration itself and policies on immigration from various destination countries. The division between high skilled labour and nonskilled labour is very difficult, especially if we are talking about the data. So, even the concept is very clear between the two categories, some data are very difficult to get. Mostly countries do not keep the record of the outmigration of high skilled people. For example, Indonesia may record the outmigration of non-skilled labour, but cannot track the high skilled outmigration. The only data available to be searched is by rough estimation, without validating whether the data is correct or not.

Previous studies had several research focuses and looked from different angles. A study by Forstenlechner (2009) [4] in Abu Dhabi, on the study of the perception of justice in the host country, found that self-initiated expatriates perceive justice and support from their host countries even though the consequences may not follow negative perception as quickly as they do in organizational context. Forstenlechner used 33 interviews to conclude the subjective points of views on the condition.

There are various impacts on highly skilled workers' migration. One negative, yet distinctive, consequence is brain drain in sending countries. Brain drain phenomenon has been studied for the last 50 years, originated from the British Royal Society as an explanation for the exodus of scientists and technologists from the United Kingdom in the 1950s and 1960s (Gibson \& McKenzie, 2011: 3) [5]. Whether brain drain increases over the years or not, one argument explained that skilled migration is definitely increasing over time but skill levels in sending countries are also increasing. Therefore, the brain drain rate may stay stable for long periods of time and may have fallen in the past decade (Gibson \& McKenzie, 2011: 7) [5].

\subsection{Political Stability}

Political stability of a country determines not only the nation's security, but also economic and social condition in a country. Many cases where political stability in a country is low, the migration rate is relatively high. Countries, such as Iran and several countries in Africa, have lost their high skilled workers to developed countries merely because of the political situation in their home country.

Bertocchi and Strozzi (2008) [6] studied the determinants of international migration with special attention to the role of institutional factors other than economic and demographic fundamentals, which resulted in significant factors of attraction, even after controlling for their potential endogeneity through a set of instruments exploiting colonial history and the institutions inherited from the past; and all is represented by political and migration institutions. A study by Breunig et al. (2012) [7] counter the cases of unstable political condition of a country; they claimed that polity of the sending country has a positive effect on migration but negative effect on the receiving country, which means that the number of migrants is affected by the barriers to entry and freedom of exit from sending and receiving country.

\subsection{Career Path}

Career development is the one motivation of people to move, whether it is to other companies or other countries. In this context, the seeking for better level of professionalism with better social and economic benefits; and in 
some times, it can be found by moving to another country. People with tertiary degree generally look for the better condition for them and for their loved ones. Within the context of this paper, people move to fill in the highly qualified occupations, which the natives supplies qualified are not enough or not qualified enough. The majority of skilled migrants are in the professions of computer specialists, accountants, managers, and scientists and academics [5].

For highly skilled people, the opportunity to develop their career is important. For example, in some cases for students, the push factors that influence them to remain the host countries are economic instability, bureaucratic obstacles, lower expected income, and little possibility for advancing in career. Meanwhile, the pull factors are better prospects for career advancement, greater opportunity for further development in the specialized area of study, and the existence of a more organized and ordered environment in general [8]. While according to Forstenlechner (2010) [4], working climate can be influenced by the national culture or relevant regulations. This may affect the condition of a person to stay in a country or return because he or she does not feel comfortable to work in particular countries.

Meanwhile, the countries where the research was implied show different results. The management of immigration in France permits inflows of skilled migrants and yet presented strong barriers to their employment and career advancement, which implied that receiving countries' policies have impact on the development of highly skilled workers [9].

\subsection{Binary Logistic Regression Model}

Binary logistic regression model is a common methodology to describe the relationship between independent variables and dichotomy dependent variable. The important implication in this model is the probability in which independent variables influence the dependent variable, another important implication is the odds ratio or likelihood ratio that the dependent variable is 1.

$$
p=\frac{\exp ^{\left(a+b_{1} x_{1}+b_{2} x_{2}+b_{3} x_{3} \cdots \cdots\right)}}{1+\exp ^{\left(a+b_{1} x_{1}+b_{2} x_{2}+b_{3} x_{3} \cdots \cdots\right)}}
$$

Equation (1) shows the mathematical function of logistic regression; which $p$ is the probability that a case is in a particular category. Exp is the exponential function (normally 2.72), $a$ is the constant of the equation and $b$ is the coefficient of the predictor variables or as we call it independent variables. When the probability fail to reach the $5 \%$ significance level, we retain the independent variables has no increased effects in predicting the dependent.

There are two hypotheses in the model that needs to be considered:

1. The null hypothesis, which is when all coefficients in the regression equation take the value zero, and

2. The alternate hypothesis that explains that the models with predictors currently under consideration is accurate and differs significantly from the null of zero (i.e. gives significantly better than the chance or random prediction level of the null hypothesis) [10].

\section{Methodology}

In the past, we had conducted survey to collect several important values that would be seminal for the modelling and simulation in this study. The target of respondents is divided into two main categories: students and professionals, each of which has finished or is currently studying in bachelor program level (minimum tertiary education level). More importantly, the area of studies is concentrated in science and engineering level, although several respondents may come from different background from the targeted fields. For professionals, the similar education background applies for target respondents. However, the choices for professionals are more flexible. For this paper, we combine the results from students and professionals, which include the characteristics, future plans, and variables' (given) importance.

The result then will be analyzed through descriptive statistics and later using binary logistic regression analysis. So far, 50 replies have been collected (36 students and 14 professionals). Replies, even though considered small, have shown influence in decision making and future estimation for mobility of Indonesian scientists and engineers. The respondents are concentrated in three particular countries: Indonesia, Japan, and Germany; the countries of education background for professionals, though, are more varied. 


\section{Results}

\subsection{Descriptive Analysis}

The initial analysis is to give descriptive information about respondents. In this study, as mentioned earlier, respondents are limited to students and professionals who are expected to have minimum tertiary education background or currently pursuing education. The target respondents education background or profession is concentrated in science and engineering area, and respondents are currently studying or working abroad. Giving the circumstance, respondents' data has been considered not very plentiful. However, the results are expected to gain its originality by receiving direct response, instead of searching from public data source.

The major proportion of respondents' gender is male (80\%) in total (students and professionals). In the case of respondents' age, for students, the majority of respondents are in the range of 20 - 24 years old, which indicate most of the respondents are currently studying in bachelor level degree; then followed by the age range of 15 - 19 years old, which also indicate the same degree pursuit. For professionals, the age range is mostly 25 - 29 years old, followed by the age range of 30 - 34 years old. The result suggests that most respondents have worked for less than 3 until 5 years. If we combine both types of respondents, 44 percent of respondents are in the age range of 20 - 24 years old. For most of student respondents in this study, their marital status is single; which means that it is in line with the age range below the average marital age. For professionals, most of respondents are married, followed by single and widowed or divorced, respectively.

For students who currently study in tertiary level degree, sixty nine percent of them are now in the bachelor degree; followed by master (17\%) and doctor degree (14\%). For professional respondents, half of the respondents have master degree followed by bachelor and doctoral degree, respectively. In total, sixty percent of respondents have or currently pursue bachelor degree; while twenty six percent of the respondents belong in master degree and the rest is doctor degree.

For professionals, most of respondents receive their degree(s) in Indonesia, followed by Germany, Japan, United Kingdom and Australia, respectively. This result indicates that Indonesia is still the main destination for respondents to pursue education. However, the count of country where respondents pursue or had pursued their education may overlap; it means that a respondent who graduated from master degree in Indonesia's university had previously graduated from bachelor degree abroad, or vice versa. For students, most of them are currently pursuing their education in Germany (70\%), which indicates the current domicile for most respondents are in Germany. The second destination country is Japan (22\%), while the rest is Indonesia (8\%).

Even though the country where respondents are currently pursuing or had pursued their education is concentrated in several countries, the fields of study vary more than the domicile. Economy studies and Information technology stand out among other fields; other fields of study include Energy and environment, Psychology, Molecular biology, Geodesy, Marine bio-resources chemistry or fisheries science, public health science, electronics, industrial technology, transportation, chemical engineering, mechanical or machinery engineering, biotechnology, mechanic electronic, and civil engineering.

Each student has his/her own point of view on future plans. In the survey, students were asked about their return intentions; if students are educated abroad whether they will return home or remain abroad, and if students are educated in Indonesia whether they will move abroad or remain in Indonesia. For students abroad, over fifty percent of students abroad choose to return home after they graduate. Almost forty percent of students abroad choose to remain in their host countries, and the rest gave no answer to this matter (6\%).

As for the future plan after graduation, students were given several options on what or where they will do: (1) continuing studies, (2) working in management area in private companies, (3) working in management or administration area in government institutions, (4) working based on specialization area in private companies, (5) working based on specialization area in government institutions, (6) working in universities, and (7) other options.

As shown in Table 1, students prefer to continue their study and work based on their specialization area in private companies, equally. For students who plan to continue their study, mostly are bachelor students. Aside from that, the result indicates that private companies are more attractive for students as a working destination for students. The next most popular option for students is working based on specialization area in government institution and "other" option, equally. "Other" option generally includes establishing their own company based on the major of their study. Interestingly, the least interesting work field for respondents is working in management 
area in private companies. Logically, management area in private companies is very popular among students because the career path is more distinctive and promising compared to other institutions or working in other areas beside management. Working in universities is also an unpopular work field option for students with only eight percent choose to work in this field. However, working in universities requires postgraduate degree (master or doctor), meanwhile as mentioned earlier, most of respondents are bachelor students. Hence, it is expected to have that kind of result.

For professionals, several questions had been asked differently from students respondents. When they were asked to classify their occupations, first rank option was "other” occupation, and it was followed by researcher occupation. "Other” occupation generally was management position in a company (i.e. banking) or in government institution (i.e. Indonesian election institution and Indonesian embassy). In the survey, we cannot be certain that respondents' major of study is in line with their profession currently. Therefore, what we can count on is their current profession and trying to classify their occupation. After researcher (29\%), Academician (21\%) followed, and then engineer (14\%). Surprisingly, none of the respondents marked scientist as their occupation, which ideally there should be.

The future plan for professional respondents varies accordingly to their occupations. For professionals who work in management, most of them are more concerned about the career path where they work, or even try to find another company to work for with faster career path and higher salary and position; and even some of them choose to be entrepreneurs or continue their study for their future plan. For other occupations, their future plans are not different from their current employment; instead of moving to other institutions or universities, they focus more on their improvements of their work, such as teaching, publication, and research improvements.

\subsection{Binary Logistic Regression Analysis}

But how much and how significant those variables affect the people's decisions to stay in a country? One of the purposes of this paper is to show the influence of people's decision making on whether to be in Indonesia or abroad for their future plans. The dependent variable is shown in the intention of staying for respondents:

1) For students abroad, the choice is whether to return home or remain abroad after they graduate.

2) For students in Indonesia, the choice is whether to remain in Indonesia or move abroad after they graduate.

3) For professionals abroad, the choice is whether to return home or remain abroad for their future plan (the next 3 - 5 years).

4) For professionals in Indonesia, the choice is whether to remain in Indonesia or move abroad for their future plan (the next 3 - 5 years).

Hence, the dependent variable only consists of two choices: staying in Indonesia and staying abroad. The condition of these choices is reflected by 0 (zero) as staying in Indonesia and 1 (one) as staying abroad as their future plans. This part discusses about the analysis of binary logistic regression using SPSS software.

Table 2 shows the classification table of step 0 when variables are not yet included in the calculation. It shows that overall percentage is 66 percent, which means that the choice of people staying in Indonesia will be correct 66 percent of the time. Next, we will see the comparison between Table 2 where variables are not included and Table 3 where variables are included to see whether the adding of variables will increase the percentage of accuracy, with choice to stay in Indonesia (indicated by 0 ) by $93.9 \%$ and choice to stay abroad (indicated by 1 ) by $17.6 \%$; and results the overall percentage of $68 \%$. Therefore, we can conclude that the mode is better than not having variables included at all.

-2 Log Likelihood scores 57.682; Nagelkerke R square indicates that the model has 16.7 percent relationship between predictors and prediction. Based on chi-square test ( $p=3.950$ with degree of freedom 5), the model shows that variables in this model is not independent. However, the correlation between political stability and career path is small and negative.

The Hosmer and Lemeshow test shows that this predicted model is not significantly differ from the observed case (Significance $=0.557$ ). The result still indicates that there is almost certainty that students and professionals choose to stay in Indonesia when they are educated or living in Indonesia, or moving to Indonesia after they are educated or living abroad. Although the significance test is not what is expected, this result will be essential on the relationship between career path and political stability, and the decision of respondents to stay in Indonesia.

For career path variable, the odds for people to move or stay abroad are almost 3 times. Meanwhile, the increase of one unit of political stability will increase the chance of people to stay abroad by $50 \%$. 
Table 1. Classification Table ${ }^{\mathrm{a}, \mathrm{b}}$.

\begin{tabular}{|c|c|c|c|c|c|}
\hline & \multirow{3}{*}{ Observed } & & \multicolumn{3}{|c|}{ Predicted } \\
\hline & & & \multicolumn{2}{|c|}{ Staying.Intention } & \multirow{2}{*}{ Percentage Correct } \\
\hline & & & 0.00 & 1.00 & \\
\hline \multirow{3}{*}{ Step 0} & & 0.00 & 33 & 0 & 100.0 \\
\hline & Staymg.mintention & 1.00 & 17 & 0 & 0.0 \\
\hline & \multicolumn{2}{|c|}{ Overall Percentage } & & & 66.0 \\
\hline
\end{tabular}

a. Constant is included in the model. b. The cut value is 0.500

Table 2. Classification Table ${ }^{\mathrm{a}}$.

\begin{tabular}{|c|c|c|c|c|c|}
\hline & \multirow{3}{*}{ Observed } & & \multicolumn{3}{|c|}{ Predicted } \\
\hline & & & \multicolumn{2}{|c|}{ Staying.Intention } & \multirow{2}{*}{ Percentage Correct } \\
\hline & & & 0.00 & 1.00 & \\
\hline \multirow{3}{*}{ Step 1} & & .00 & 31 & 2 & 93.9 \\
\hline & Staying.Intention & 1.00 & 14 & 3 & 17.6 \\
\hline & \multicolumn{2}{|c|}{ Overall Percentage } & & & 68.0 \\
\hline
\end{tabular}

a. The cut value is 0.500 .

Table 3. Variables in the Equation.

\begin{tabular}{|c|c|c|c|c|c|c|c|c|c|}
\hline & & \multirow{2}{*}{ B } & \multirow{2}{*}{ S.E. } & \multirow{2}{*}{ Wald } & \multirow{2}{*}{ df } & \multirow{2}{*}{ Sig. } & \multirow{2}{*}{$\operatorname{Exp}(B)$} & \multicolumn{2}{|c|}{ 95\% C.I. for $\operatorname{EXP}(B)$} \\
\hline & & & & & & & & Lower & Upper \\
\hline \multirow{3}{*}{ Step $1^{\mathrm{a}}$} & Career.Path & 1.096 & 0.602 & 3.321 & 1 & 0.068 & 2.993 & 0.921 & 9.730 \\
\hline & Pol.Stabil & -0.551 & 0.350 & 2.481 & 1 & 0.115 & 0.576 & 0.290 & 1.144 \\
\hline & Constant & -03.420 & 2.646 & 1.671 & 1 & 0.196 & 0.033 & & \\
\hline
\end{tabular}

a. Variable(s) entered on step 1: Career. Path, Pol. Stabil.

\section{Conclusions and Further Improvement}

This study tries to analyze the decision made by Indonesian students and professionals mainly in the science and technology areas on staying preferences as their future plan. And this paper has collected 50 questionnaires, which is enough to be analyzed using binary logistic regression. Descriptive analysis shows that the questionnaire is dominated by students. Therefore, most respondents are male, in the range of $20-24$ years old, and have not been married. Student respondents are dominated with the pursuit of bachelor degree while professionals have graduated from master degree. For students, most are currently studying in Germany; and most professionals have their degree gained in Indonesia.

Student respondents' field of study vary more than their country of studying, and their future plans are also distributed with most choose to continue their studies. For professionals, their occupation is mostly in management field in a company, followed by researcher, academicians, and engineer. For most respondents, their future plans are going back to Indonesia or remaining in Indonesia rather than staying abroad.

Career path and political stability are analyzed in order to know their relationship with decision of students and professionals as their future plans. First, the correlation between both variables is small and negative, which means that both variables are independent. Second, career path will increase the chance of people to move abroad or stay abroad almost 3 times likely, while political stability will increase the odds of people to stay abroad by $50 \%$.

Further improvement needs to be conducted in this paper. First of all, the samples of this paper are adequate, 
but not enough to make significant conclusion. By collecting more samples the result may be more significant than previous one. Second, this paper combined both samples from students and professionals; for further improvement, if more samples can be collected, samples can be divided into two groups and then will be deliberately distinguished the differences.

\section{References}

[1] Fatah, F.A., Othman, A. and Abdullah, S. (2012) Economic Growth, Political Freedom and Human Development: China, Indonesia, and Malaysia. International Journal of Business and Social Science, 3, 291-299.

[2] Iredale, R. (2000) Migration for the Highly Skilled in the Asia-Pacific Region. The International Migration Review, 34, 882-906.

[3] OECD, 2009-2010-2011. OECD Statistics Database. http://stats.oecd.org

[4] Forstenlechner, I. (2010) Exploring Expatriates’ Behavioral Reaction to Institutional Injustice on Host Country Level. Personnel Review, 39, 178-194. http://dx.doi.org/10.1108/00483481011017408

[5] Gibson, J. and McKenzie, D. (2011) Eight Questions about Brain Drain. Journal of Economic Perspectives, 25, 107128. http://dx.doi.org/10.1257/jep.25.3.107

[6] Bertocchi, G. and Strozzi, C. (2008) International Migration and the Role of Institutions. Public Choice, 137, 81-102. http://dx.doi.org/10.1007/s11127-008-9314-X

[7] Breunig, C., Cao, X. and Luedtke, A. (2012) Global Migration and Political Regime Type: A Democratic Disadvantage. British Journal of Political Science, 42, 825-854. http://dx.doi.org/10.1017/s0007123412000051

[8] Gungor, N.D. and Tansel, A. (2008) Brain Drain from Turkey: The Case of Professionals Abroad. International Journal of Manpower, 29, 323-347. http://dx.doi.org/10.2139/ssrn.962373

[9] Ariss, A.A. (2010) Modes of Engagement: Migration, Self-Initiated Expatriation, and Career Development. Career Development International, 15, 338-358. http://dx.doi.org/10.1108/13620431011066231

[10] http://www.uk.sagepub.com/burns/website\%20material/Chapter\%2024\%20-\%20Logistic\%20regression.pdf 